\title{
NUMERICAL SIMULATION OF IRREGULAR WAVES RUNUP ON A BEACH
}

\author{
Luning Sun, University of Notre Dame, Isun7@nd.edu \\ Andrew Kennedy, University of Notre Dame, Andrew.B.Kennedy.117@nd.edu
}

\begin{abstract}
INTRODUCTION
Breaking wave induced run-up can significantly risk infrastructure in coastal areas. For instance, run-up elevation can cause coastal flooding. Moreover, the momentum flux transported onshore can also exert forces on beaches and coastal structures. This study aims at predicting shoreline forces and inundation depths via numerical simulation as well as better understanding coastal run-up events.
\end{abstract}

\section{METHOD}

A set of 1 hour simulations are performed using SWASH (Simulating WAves till SHore). The simulations use both two dimensional and three dimensional domains to understand the effect of directional spreading angle $\sigma_{\theta}$. Five representative slopes $(0.01,0.02,0.04,0.06,0.10)$ are used to determine the effect of slope to run-up. The bottom roughness is counted by Manning coefficient $n$. Three different values $0.01,0.02,0.05\left(\mathrm{~s} \cdot \mathrm{m}^{-\frac{1}{3}}\right)$ are chosen to test if run-up height is sensitive to this parameter.

Irregular waves are generated by TMA spectrum, which generates wave from significant wave height $H_{0}$, peak period $T_{p}$ and directional spreading angle $\sigma_{\theta}$. In two dimensional cases directional spreading cases is $0^{\circ}$ while three dimensional cases use $10^{\circ}, 20^{\circ}$ and $30^{\circ}$. The Iribarren numbers in simulation cases range from 0.05 to 1.1. Runup boundary is determined by a moving shoreline technique where water depth greater than $0.15 \mathrm{~m}$ is considered as flooding area. Minimum prominence is 0.2 maximum run-up height in that time series to avoid finding the false peak. Figure 1 shows an example of run-up series.

\section{RESULTS}

Numerical run-up results are compared to existing empirical formula proposed by Stockdon (2006) and two percent exceedance run-up is used for comparison. The results shows that two dimensional run-up elevation is used for comparison. The result shows that two dimensional run-up height is always higher than Stockdon's formula because it doesn't account for directional spreading effects, as shown in Figure 2 to Figure 4. The points lies in red square correspond to $\xi_{0}<$ 0.3 , which is the distinction between dissipative and intermediate beach. Furthermore, the increasing of friction can reduce the run-up height to some degree. In three dimensional cases, directional spreading angle $\sigma_{\theta}$ plays an important role in mitigating run-up height. Result shows that Stockdon's formula are very close to numerical results when $\sigma_{\theta}=30^{\circ}$, as shown in Figure 5, indicating that these simulations statistically reproduce Stokcdon's equation.

Furthermore, my study calculates $0.5 \%$ exceedance dimensionless momentum flux, noting its variation with different deep water Iribarren numbers $\xi_{0}$, dimensionless elevation $\eta^{*}$ and directional spreading angle $\sigma_{\theta}$. Result shows that the extreme momentum flux decreases with $\eta^{*}$ and $\sigma_{\theta}$. Furthermore, given a location, waves with higher deep water Iribarren number $\xi_{0}$ correspond to higher momentum flux. However, it cannot be predicted accurately as a function of aforementioned parameters. Instead, a simple expression Equation 1 is proposed to approximate the extreme momentum flux when $\sigma_{\theta}=30^{\circ}$ for design purpose, the qualitative goodness of fitting is shown in Figure 6.

$$
M^{*}=\left(0.2071 \xi_{0}-0.0217\right) \cdot\left(10^{-2.63 \cdot\left(\frac{\eta^{*}}{1.1008 \cdot \xi_{0}^{0.4967}-0.136}\right)^{2}}\right)
$$

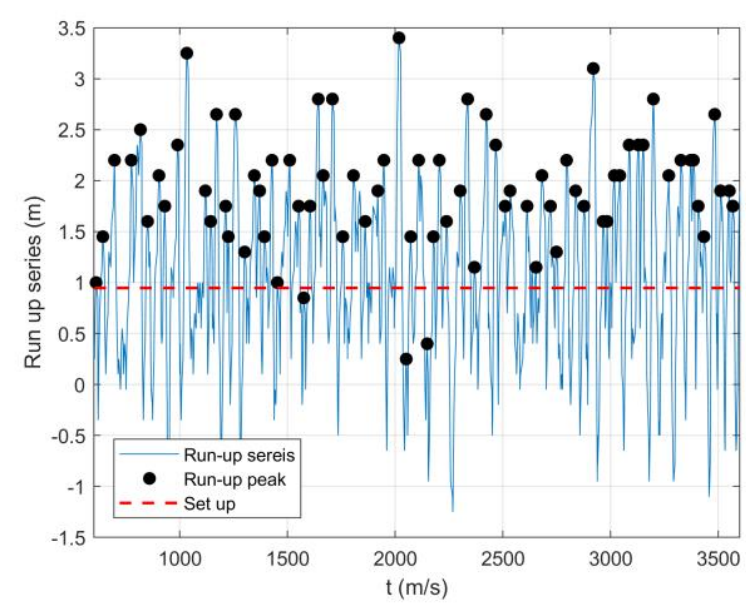

Figure 1 Example for finding peaks in Run-up series.

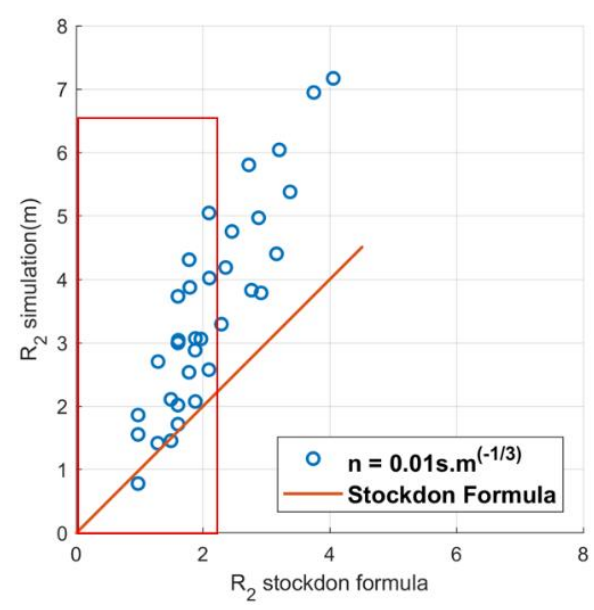

Figure $2 R_{2}$ comparison between Stockdon formula and simulation result $n=0.01 \mathrm{~s} \cdot \mathrm{m}^{-1 / 3}$ 


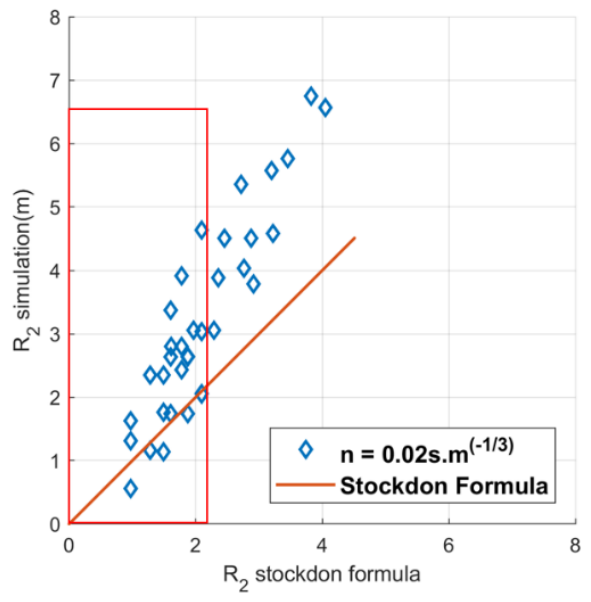

Figure $3 R_{2}$ comparison between Stockdon formula and simulation result $n=0.02 \mathrm{~s} \cdot \mathrm{m}^{-1 / 3}$

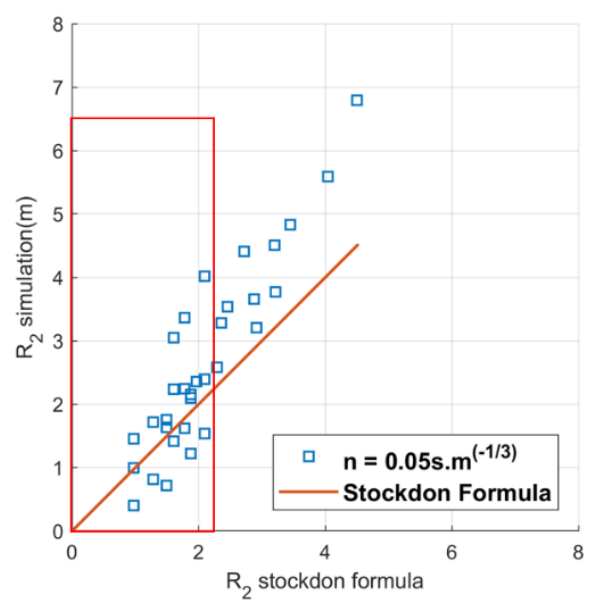

Figure $4 R_{2}$ comparison between Stockdon formula and

Figure 5 Run-up comparison when $\sigma_{\theta}=30^{\circ}$ simulation result $n=0.05 \mathrm{~s} \cdot \mathrm{m}^{-1 / 3}$

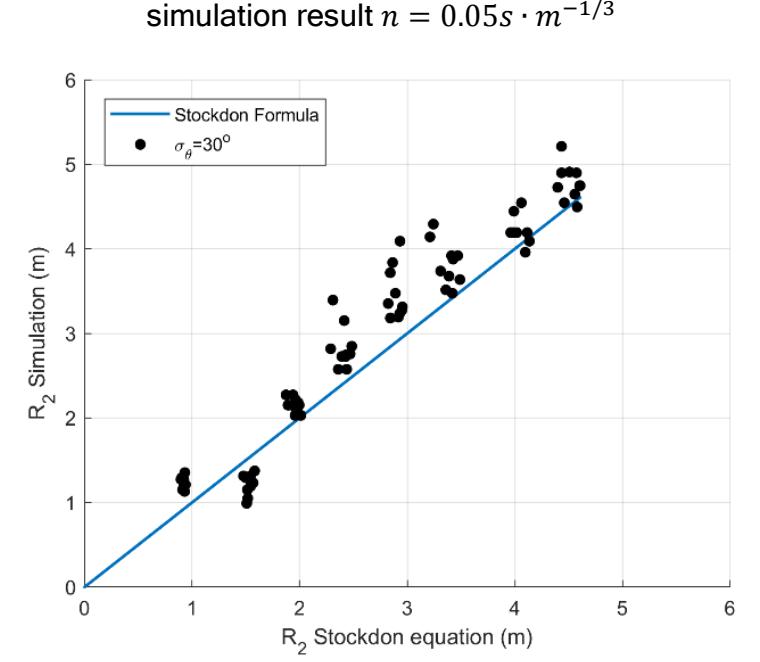

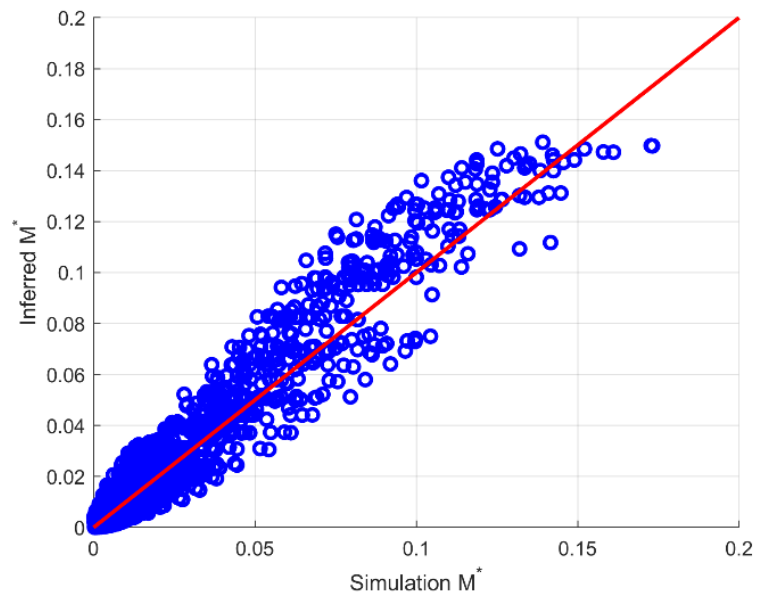

Figure 6 One on one plot for the momentum flux when $\sigma_{\theta}=30^{\circ}$ using equation 1 .

\section{REFERENCES}

Stockdon, Holman, Sallenger (2006): Empirical parameterization of setup, swash and run-up, Coastal Engineering, ELSEVIER, vol. 53, pp. 573-588.

The SWASH team (2017): Swash manual v $4.01 \mathrm{~A}$ 